\title{
Measuring circadian cycles: A simple temperature recording preparation
}

\author{
RAYMOND G. ROMANCZYK, DANIEL B. CRIMMINS, WILLIAM C. GORDON, \\ and WAYNE M. KASHINSKY \\ State University of New York, Binghamton, New York 13901
}

\begin{abstract}
While measurement of temperature as an index of circadian rhythmicity is not a difficult task with infrahuman subjects, long-term monitoring of deep body temperature with human subjects poses numerous measurement and safety problems. A preparation is described that is highly accurate, inexpensive, chronic, comfortable, and eliminates safety problems associated with more traditional methods of temperature measurement.
\end{abstract}

Circadian rhythms, the fluctuations of several biological functions over a 24-h period, have been found to correlate with a variety of behavioral measures. Research with infrahumans has revealed a number of significant relationships between circadian rhythms and processes such as learning, memory, and motivation (e.g., Stephens \& McGaugh, 1968; Stroebel, 1967; Ternes, 1976). Of particular interest are recent studies which suggest that both adult and child psychotics exhibit abnormal circadian rhythm functions (Hill, Wagner, Shedlarski, \& Sears, in press; Morgan \& Cheadle, 1976).

Finding practical and appropriate methods for measuring circadian fluctuations in disturbed subjects is problematic. Perhaps the easiest and most reproducible rhythm that can be measured is deep body temperature. However, the use of an oral or rectal thermometer carries with it the risk of injury to an uncooperative subject as well as inaccuracies in measurement. Another disadvantage is that subjects must be awakened throughout the sleep cycle if measures are to be taken hourly.

The present report describes a preparation which is accurate, safe (even with uncooperative subjects), comfortable for the subject, relatively inexpensive (the unit sells for less than \$7), and can serve as a chronic preparation that can also be used with a sleeping subject.

\section{METHOD}

A commercially available thermistor (YSI Products No. 44006$)^{1}$ is the basic component. Each of the connecting wires to the thermistor is insulated through the use of plastic tubing and a sheath of heat shrinkable tubing is placed over both wires up to, but not covering, the thermistor head. The connecting wires to the thermistor may then be soldered and insulated to the subject cable (2-conductor, 18-gauge wire is adequate) (Figure 1).

Requests for reprints should be sent to Raymond G. Romanczyk, Department of Psychology, State University of New York, Binghamton, New York 13901. The authors wish to thank Evan Graber for his preparation of the illustrations.
The method of application to the subject is straightforward. The probe is typically placed under the arm of the nonpreferred hand, as shown in Figure 2. As a final step, the cable is brought behind the subject and up to the shirt collar area. As a strain relief, a piece of Micropore ${ }^{2}$ tape is placed over the cable approximately midway between the shoulder blades.

The subject may be dressed in whatever clothing is suitable. Temperature readings are taken simply by attaching the cable to an ohmmeter (a digital type is preferable) with the subject's arm by his side, allowing the meter to stabilize for approximately $1 \mathrm{~min}$. The ohm reading is converted into degrees Celsius utilizing the conversion chart provided by the manufacturer with each thermistor.

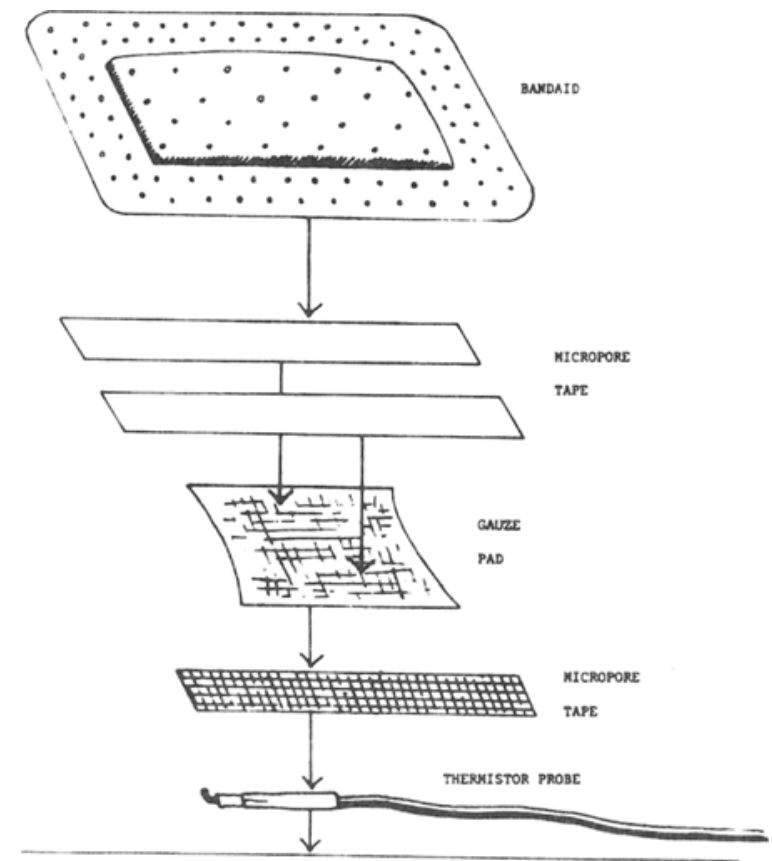

Figure 1. Schematic of adhesion of the thermistor to the subject. 


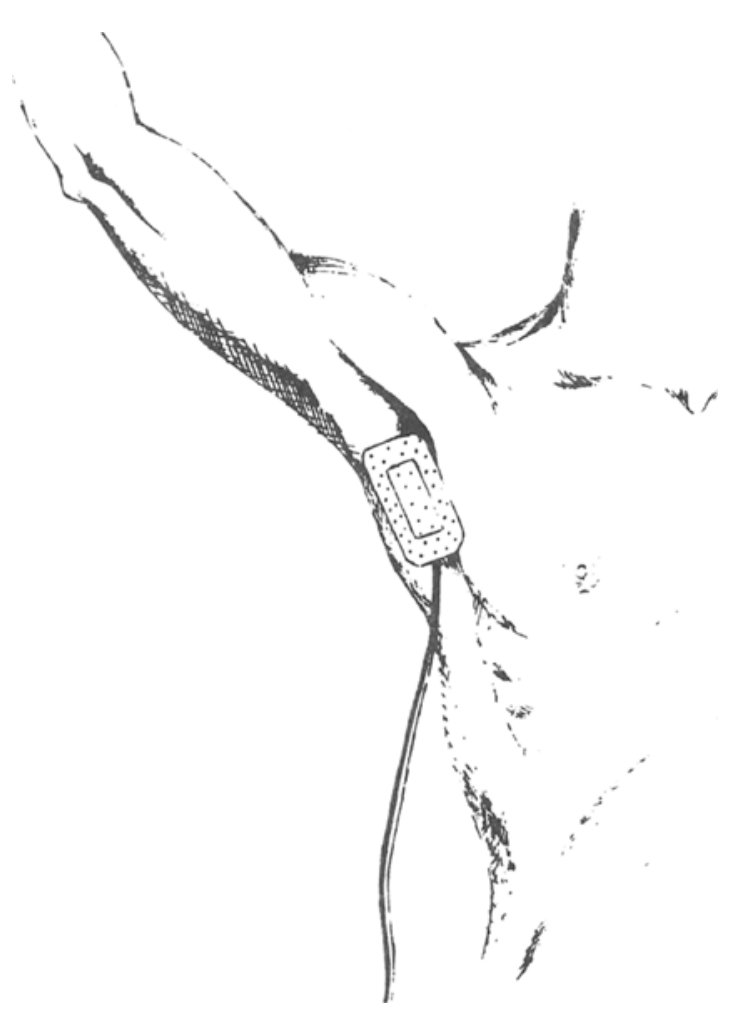

Figure 2. Site for thermistor placement.

We have used this preparation to obtain temperature data on both normal and disturbed children. In order to validate the accuracy and reliability of this preparation, we obtained not only axillary temperature readings (as described above) but also rectal temperatures. To record rectal temperatures, a YSI Products thermistor matched to the one used above was installed in a metal-tipped plastic rectal probe. This insured that the sensing devices were initially calibrated and that any differences arising would be due to preparation differences. Our subject was a 6-year-old severely disturbed female child who lived-in at our research facility. Both axillary and rectal temperatures were taken simultaneously every hour on the hour for a 24-h period. The rectal probe was inserted for a period of 3 min before readings were taken to allow the unit to stabilize.

\section{RESULTS}

The data were averaged by 2 -h blocks, thus yielding 12 data points. The correlation between the axillary and rectal temperatures was .96 . These results are presented graphically in Figure 3. As can be seen, there is a slight, almost constant temperature differential between the

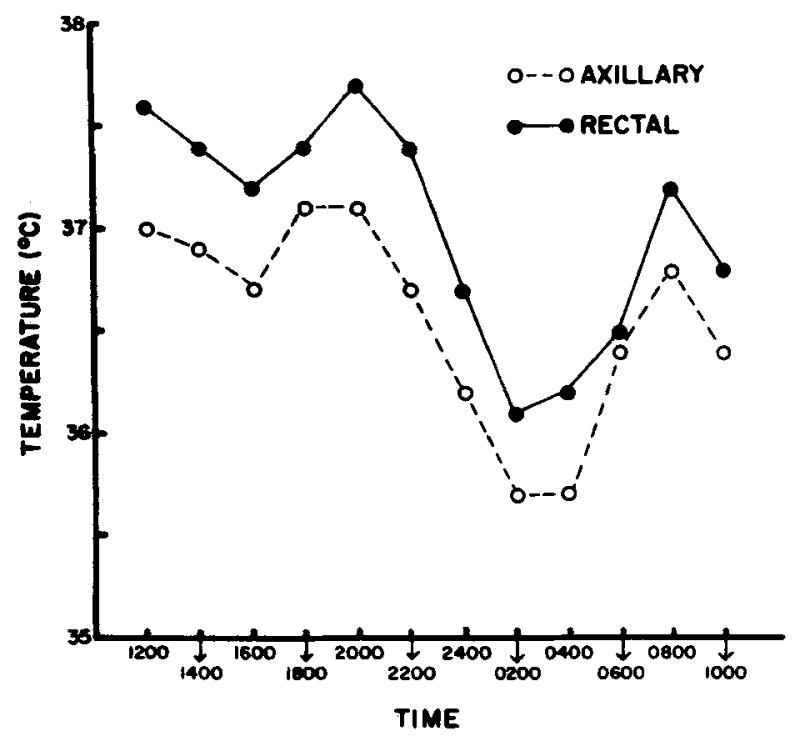

Figure 3. Temperature readings of the axillary and rectal preparations over a 24 -h period.

two preparations, and the two curves are virtually identical with respect to form. The data clearly indicate that the axillary preparation is highly accurate and reliable.

\section{REFERENCES}

Hill. S. D.. Wagner, E. A., Shedlarski, J. G.. \& Sears, S. P. Diurnal cortisol and temperature variation of normal and autistic children. Developmental Psychology. in press.

Morgan, R., \& Cheadle. A. J. Circadian body temperature in chronic schizophrenia. British Journal of Psychiatry. 1976, 129, 350-354.

Stephens, G., \& McGauch, J. L. Retrograde amnesia: Effects of periodicity and degree of training. Communications in Behavioral Biology. 1968. AI. 267-275.

Stroebel, C. F. Behavioral aspects of circadian rhythms. In J. Zubin \& H. F. Hunt (Eds.), Comparative psychopathology. New York: Grune \& Stratton, 1967.

Ternes, J. W. Resistance to extinction of a learned taste aversion varies with time of conditioning. Animal Learning \& Behavior. 1976, 4, 317-321.

\section{NOTES}

1. Industrial Division, Yellow Springs Instrument Company, Yellow Springs, Ohio 45387.

2. We have found Micropore tape to be particularly suitable for adhesion. Micropore is a registered trademark of the $3 \mathrm{M}$ Company.

(Received for publication April 26, 1977; revision accepted May 12, 1977.) 